TP maakt in deze rubriek een selectie uit het aanbod van productintroducties. Heeft u nieuwe producten die u onder de aandacht wilt brengen, mail dan naar: tandartspraktijk@bsl.nl

Tekst en foto's: Sander Loos

\title{
TP IDS 2021: waar was iedereen?
}

Het kan de dag zijn geweest, maar de International Dental Show (IDS) 2021 leek toch minder druk bezocht dan eerdere edities.

Op zaterdag 25 september was het vrij leeg in de hallen van de Kölnmesse in Keulen en hielden veel standhouders zich meer bezig met hun mobiele telefoons dan met potentiële klanten. Dat gaf dan weer wel alle ruimte om er op het gemak wat highlights uit te pikken.

Wat meteen opviel, was de toename van het aantal Chinese leveranciers. Van composieten, instrumentarium, implantaten tot röntgenap- paratuur. Zo'n beetje alles wordt tegenwoordig (ook) geproduceerd in China. Maar niet alleen Chinezen hebben hun weg gevonden naar de grootste dentale vakbeurs in Europese, ook Arabische en Indiase standhouders waren vertegenwoordigd.

NeedleOff was een van de Nederlandse bedrijven die zich wilden laten zien. Het is de producent van een vernuftig apparaatje dat geheel automatisch de naald van de anesthesie spuit verwijdert. Een heuse Nederlandse vinding. De redactie van TP kreeg als dank voor het bezoek aan de stand twee pennen cadeau. lets prominenter aanwezig was het Nederlandse NoviaCura. NoviaCura is gespecialiseerd in het organiseren van professionele mondzorg voor zorgafhankelijke cliënten van (zorg)instellingen, die niet langer in staat zijn zelfstandig een mondzorgprofessional te bezoeken. Door de mondzorg naar de (zorg)instellingen toe te brengen maken ze die zorg op een veilige manier mogelijk. Dat doen ze bijvoorbeeld met mobiele tandartspraktijken: bussen en campers volledig ingericht voor patiëntenbehandeling. De bussen van NoviaCura trokken flink wat aandacht.

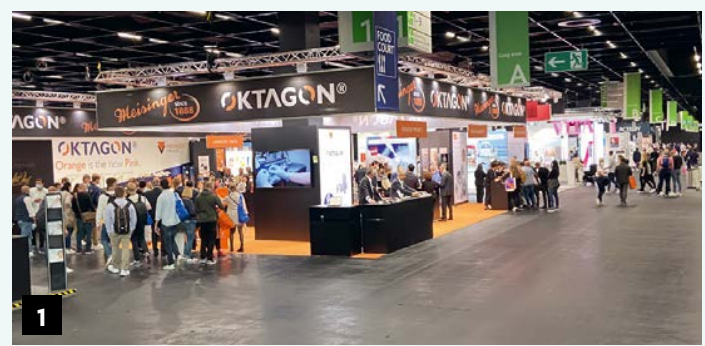

Afb. 1 Zaterdag 25 september, een rustige IDS

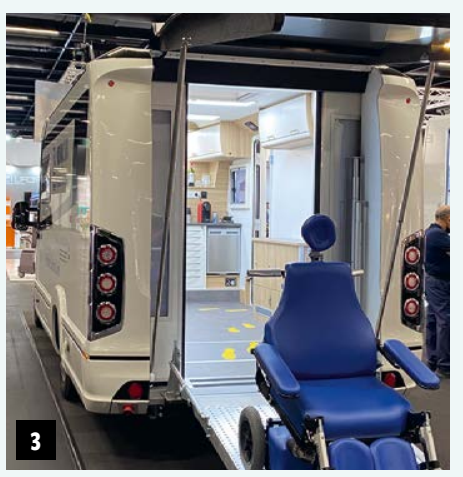

Afb. 3 en 4 De mobiele praktijkbus van NoviaCura

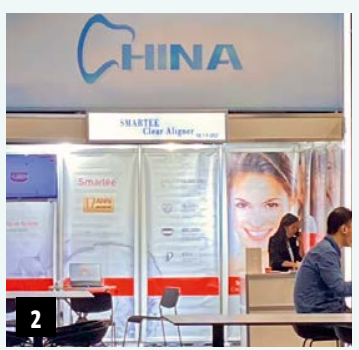

Afb. 2 Veel producten uit China op de IDS
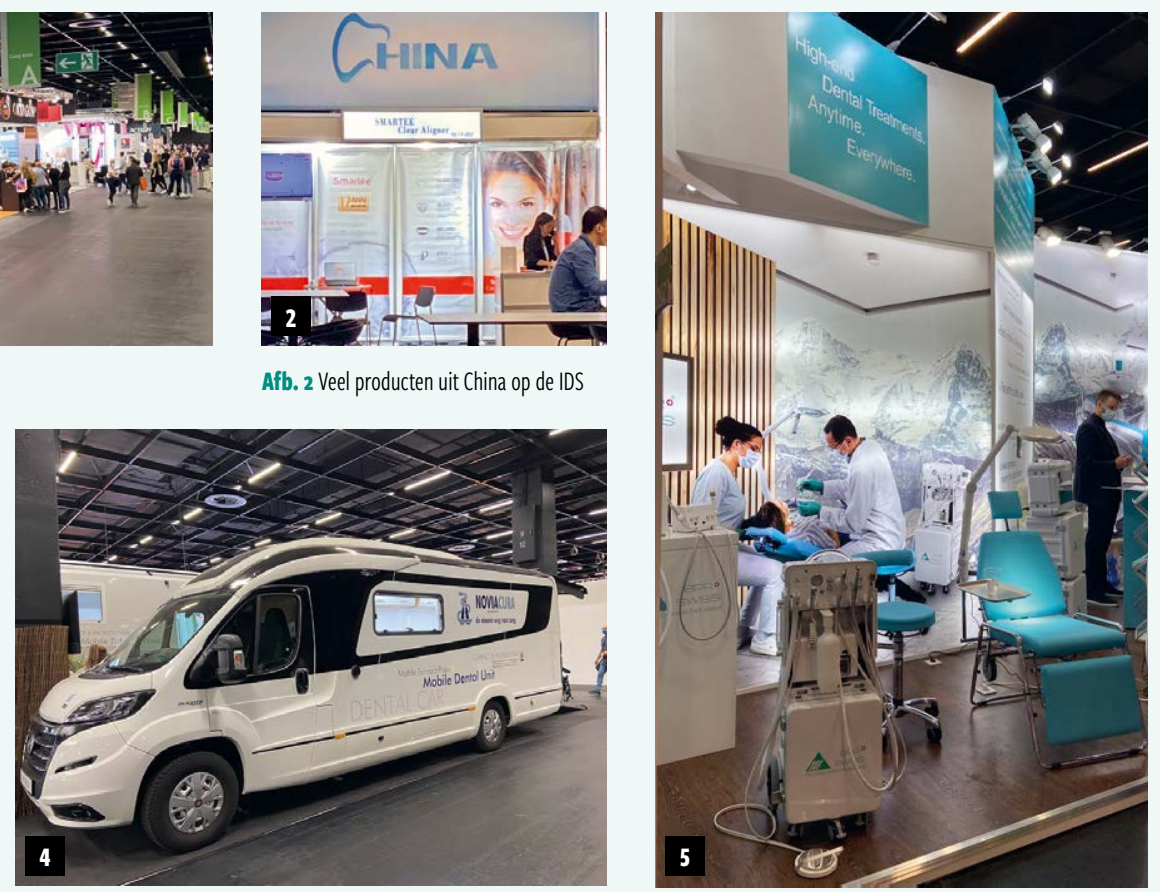

Afb. 5 Veel aandacht voor mobiele units en stoelen 


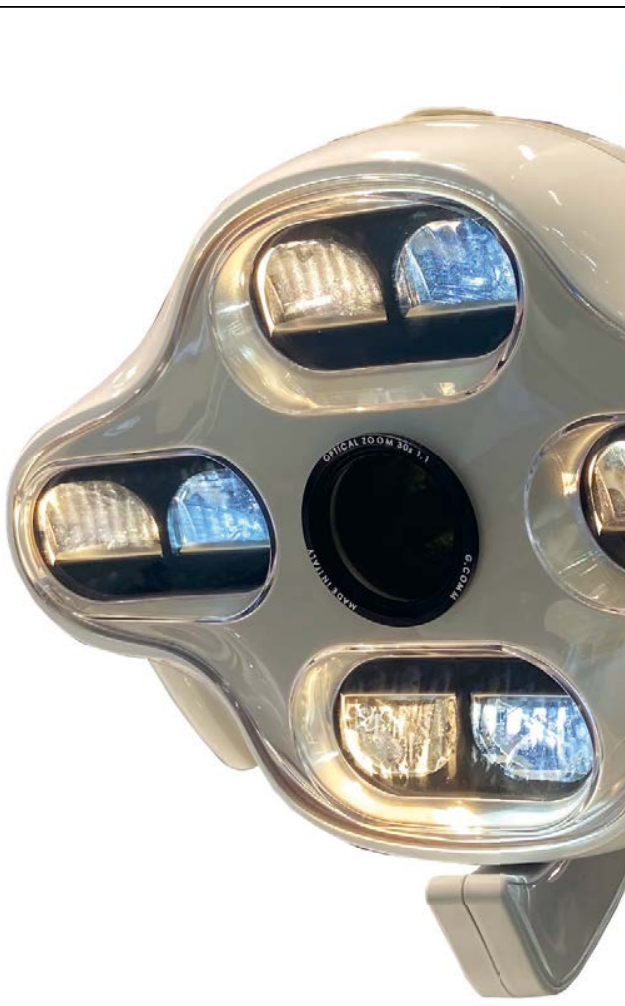

Opmerkelijk veel interesse was er ook voor mobiele behandeleenheden; units met eenvoudig te verplaatsen behandelstoelen. Blijkbaar ligt er een markt open voor zorg aan huis.

De Italiaanse afdeling lag er verlaten bij. Waar in het verleden veel aandacht was voor het traditionele Italiaanse design bleef het nu stil in de Italiaanse straten. Is design uit? En omdat we tegenwoordig alles willen en moeten vastleggen en documenteren kwam het Franse ADPG naar Keulen met de Iris View van G.COMM. Een operatielamp met een ingebouwde full HD camera met 30x zoom mogelijkheid. Een prachtige lamp met een ruime keuze uit belichtingsmogelijkheden uit acht bronnen.

Ondanks de verplichting een mondmasker te dragen op de beurs, waren we Covid 19 al bijna vergeten. Maar de fabrikanten niet! Provita stond er met de Denta Shield, een plexiglasplaat op een verrijdbare voet die je boven de patiënt kunt hangen om druppelbesmetting voor te zijn. Het zal even wennen zijn om zo te werken. Nog veiliger en gekker is het natuurlijk als je de patiënt een stofzuiger met een hele grote zuigmond boven het hoofd hangt. Wel even oppassen dat je de contactlenzen van de patiënt niet per ongeluk opzuigt.

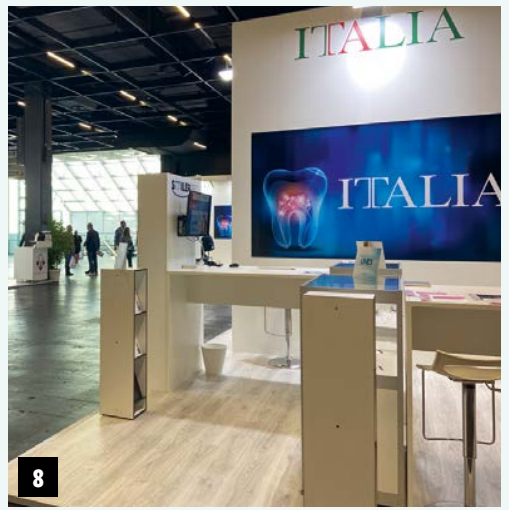

Afb. 8 en 9 Italiaans design trok niet veel belangstelling

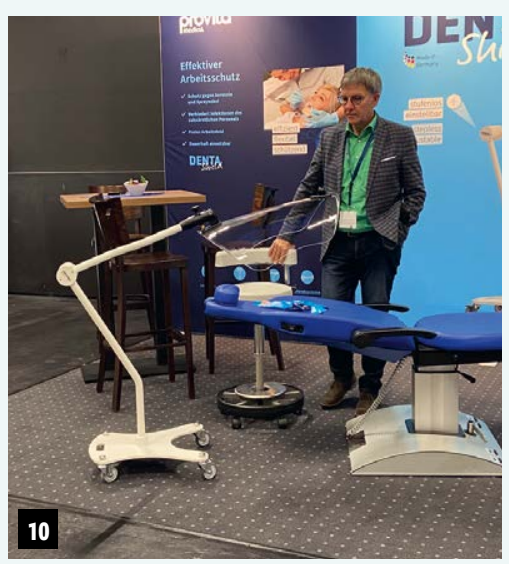

Afb. 10 en 11 De oplossing tegen druppelbesmetting?
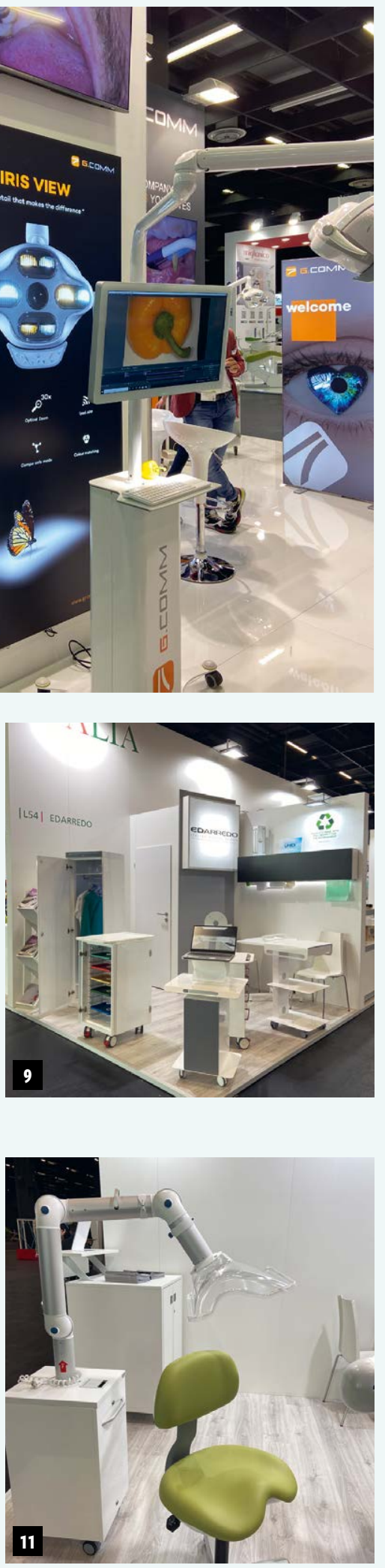

Operatielamp ebouwde full HD

videocamera
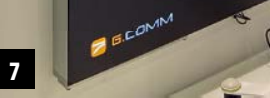

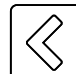

